\title{
PROFISSÃO DOCENTE: \\ desafios, perspectivas e debates contemporâneos
}

\author{
Francine Santos Gomes' \\ Tiago Melo de Oliveira² \\ Fábio Viana Santos 3
}

Silva, D. O. V. da; Oliveira, E. G.; Brito, V. L. F. de (orgs.). Questões contemporâneas sobre a profissão docente. Vitória da Conquista: Edições UESB, 2020. 270p.

A coletânea intitulada "Questões contemporâneas sobre a profissão docente", organizada por Daniela Oliveira Vidal da Silva, Eliane Guimarães de Oliveira e Vera Lúcia Fernandes de Brito, reúne pesquisadores do Programa de Pós-Graduação em Educação da Universidade Estadual do Sudoeste da Bahia (UESB), socializando importantes investigações que têm sido realizadas no âmbito do Programa, cujo foco se constitui na profissão docente. Assim apresenta múltiplos olhares sobre temas caros ao magistério como formação inicial e continuada, piso salarial, desafios da carreira, (des)valorização do magistério dentre outros.

\footnotetext{
1 Mestranda em Educação no Programa de Pós-Graduação em Educação da Universidade Estadual do Sudoeste da Bahia (PPGEd/Uesb). Membro do Grupo de Estudos e Pesquisa em Didática, Formação e Trabalho Docente (DIFORT/CNPq). Orcid iD: https://orcid.org/00000003-0864-0347. E-mail: francinegomesped@gmail.com

2 Mestrando em Educação no Programa de Pós-Graduação em Educação da Universidade Estadual do Sudoeste da Bahia (PPGEd/Uesb). Membro do Grupo de Pesquisa em Ludicidade, Didática e Práticas de Ensino (LUDIPE/CNPq): Professor da Rede Municipal de Itapetinga/BA. Orcid iD: https://orcid.org/0000-0003-3954-6169. E-mail: tiagomelo9001@gmail.com

${ }_{3}^{3}$ Mestrando em Educação no Programa de Pós-Graduação em Educação da Universidade Estadual do Sudoeste da Bahia (PPGEd/Uesb). Membro do Grupo de Estudos e Pesquisas em Práticas Curriculares e Educativa (GEPPCE/CNPq). Orcid iD: https://orcid.org/0000-0002-89787801 E-mail: fabioviana.pedagogo@gmail.com
} 
Ao objetivar trazer para cena questões contemporâneas sobre a profissão docente, as organizadoras da obra privilegiaram as diferentes temáticas. Isso ocorre exatamente porque os distintos sujeitos que compõem o programa de pós-graduação focalizam em seus estudos as questões contemporâneas nas diferentes vertentes de atuação da profissão docente. Os objetos de estudos são tratados tanto pela lente teórico-metodológica marxista, como também estudos que focalizam a fenomenologia e outros olhares que são necessários para compreender o magistério. Além disso, observa-se também que o recorte geográfico feito pela obra, reflete a área de abrangência do PPGEd/Uesb, consolidando o Programa como importante protagonista da produção acadêmica do campo educacional na região nordeste.

O primeiro capítulo "Trabalho e Desenvolvimento Profissional Docente: diferentes nuances no contexto de alargamento das políticas neoliberais", de autoria Carla David Alencar de Sena Brito, Daniela Oliveira Vidal da Silva, Emanuelle Araújo Martins Barros e Ruth Prado Trindade reflete sobre a influência do contexto político e econômico da nossa sociedade tem em relação a valorização dos professores, partindo do pressuposto de que para atender a demanda do mercado os fundamentos educacionais estão sempre baseados de acordo com a lógica do capital.

O artigo de Júlia Cecília de Oliveira Alves Ribeiro e Cláudio Pinto Nunes, intitulado por "Piso salarial profissional nacional dos professores brasileiros: lutas para conquistar e efetivar", faz um percurso relatando as lutas pelo direito do piso salarial nacional dos docentes, apontando que mesmo com a conquista, muitos professores ainda não usufruem desse direito que está estabelecido por lei, evidenciando uma grande distância entre o que está proposto na legislação educacional e e o que é posto na realidade dos professores no Brasil.

A investigação de Di Paula Prado Calazans, Cláudio Pinto Nunes e Berta Leni Costa Cardoso, "Discursos de responsabilização na política educacional contemporânea: Avaliação e Indicadores de desempenho como referenciais de qualidade", critica as reformas educacionais que 
aconteceram no Brasil, com o discurso de que todas as propostas implementadas visaram uma reformulação nas questões educacionais reconhecendo as políticas de avaliação existentes no Brasil como maneira de balancear a qualidade da educação brasileira com o discurso de que tais políticas são significativas para a melhoria da qualidade educacional, mas como apontam tais autores as políticas de avaliações não podem se limitar de forma isolada com o objetivo de alcançar metas e índices.

"Os desafios para o desenvolvimento profissional docente e os pilares para a valorização dos professores: algumas considerações" é o título do quarto capítulo, de autoria das pesquisadoras Maiane Fonseca Santos, Luciana Amorim de Oliveira e Andrecksa Viana Oliveira Sampaio aponta os desafios para o desenvolvimento profissional e as principais categorias para a valorização docente, dentre eles estão a formação inicial e continuada dos professores, as condições de trabalho e o salário.

No quinto capítulo, cujo título é "A docência em Ciências Biológicas: Reflexões sobre a formação inicial na contemporaneidade" é escrito por Matheus Bonfim Ribas, Helécia Paiva Silva Pedreira, Edinalva Padre Aguiar e Edinaldo Medeiros Carmo, faz uma discussão acerca da profissão docente na área das Ciências Biológicas, colocando em destaque a importância de uma educação superior de qualidade, sem fragmentações e tecnicismo.

Escrito por Andréa Alcantara Limpa Aguiar e Leila Pio Mororó, o capítulo intitulado "A profissionalização docente e as suas concepções em disputa" traz perspectivas acerca do conceito de profissionalização docente, destacando que uma das maiores dificuldades dos profissionais docentes hoje é de construir uma identidade, haja vista que as concepções de profissionalização dos professores, existentes são todas voltadas para o mercantilismo.

Já no sétimo artigo as autoras Janete Santos Silva e Denise Aparecida Brito Barreto refletem sobre as contribuições da leitura no processo de formação do professor. O texto intitula-se "A importância da leitura para a formação docente" e evidencia o papel da leitura na formação dos sujeitos, 
imperativa para a prática docente. Para as autoras as atividades de leituras são condições indispensáveis para a constituição da identidade docente.

As pesquisadoras Dalvani Oliveira Menezes, Simone Souto e Denise Aparecida Brito Barreto apresentam um estado da arte sobre a formação de professores no Programa de Pós-Graduação em Educação (PPGEd/Uesb). Neste estudo foram analisados 17 trabalhos produzidos nos anos de 2015 a 2018. Para a análise, as autoras dividiram os trabalhos em dois blocos: Políticas Públicas de Formação de Professor e Programas de Governo e Formação de Professores. Os resultados apontaram que os programas de governo são fundamentais para o desenvolvimento da educação brasileira e enfatizam a importância das tecnologias de informação e comunicação no contexto atual, destacando que formar professor e intervir na dinâmica do seu processo formativo é uma tarefa árdua e urgente.

O nono capítulo, de autoria de Izis Pollyanna Teixeira Dias de Freitas e Edinalva Padre Aguiar apresenta reflexões acerca do perfil e da prática docente dos professores de história de Lagoa Real-BA. Na pesquisa, as autoras identificam o perfil dos professores de história e discutem a prática docente relacionada com o planejamento pedagógico, a seleção curricular e ensino de algumas temáticas. Entre as conclusões da pesquisa, além do perfil dos docentes, a maioria são profissionais graduados na área, com experiência e possuem especialização. Ficou evidente que o sucesso ou insucesso da atuação do professor está vinculado à formação docente bem como ao desenvolvimento de saberes ao longo de sua prática, além de ter sido observada a preocupação dos professores em envolver seus alunos com temáticas ligadas à história e cultura afro-brasileira e indígena, bem como à história local e patrimonial.

A pesquisa de Julita Lopes de Carvalho aborda as tensões, conflitos e desafios dos docentes da EJA. A autora faz uma reflexão acerca das novas políticas educacionais, discutindo as possibilidades e desafios das políticas de valorização docente. A autora apresenta reflexões sobre as condições de trabalho dos docentes e suas considerações finais, destacando a importância de educadores e educandos serem reconhecidos e valorizados. 
Calila Fernandes Guimarães Jandiroba e Vitória Sena Santos Lima discutem as práticas de letramento na Educação Infantil e como elas contribuem para o processo de valorização da diversidade cultural, no artigo "Letramento e diversidade cultural: um olhar sobre o trabalho docente na Educação Infantil". As autoras apontam que a sensibilidade para as questões relacionadas às diferenças culturais vem aumentado, embora ainda possuam muitos desafios. Desta forma, é também desafio da escola encarar o letramento e a diversidade cultural como meio de transformar o ambiente escolar num espaço de "aprendizagem significativa".

O décimo segundo capítulo, de autoria de Ruthnelle de Oliveira Chagas, Cecilia Conceição Moreira Soares, Fernanda Dione Sales de Souza e Reginaldo Santos Pereira, traz uma perspectiva sobre como as transformações econômicas tem impactado a Educação de Jovens e Adultos (EJA) nas políticas públicas e nas universidades em relação à formação dos professores. Para tanto, refletem sobre o trabalho e educação no contexto do neoliberalismo e contextualizam a EJA no estado da Bahia a partir de 2009.

Os autores fazem uma discussão sobre a formação do professor da EJA num panorama apresentado pelas licenciaturas da UESB, discutindo avanços e fragilidades. Em suas conclusões, afirmam que as políticas voltadas para a EJA não têm assegurado a formação específica para os professores dentro da universidade, tendo o estudo evidenciado também o pouco preparo dos docentes para atuarem nas turmas de EJA.

No décimo terceiro capítulo, Anderson Moreira da Silva, Celina Gabriela Leite Bomfim e Edinaldo Medeiros Carmo discutem o Desenvolvimento Profissional Docente (DPD) e suas relações com as condições de trabalho, o currículo e a autonomia. Os autores destacam que é preciso despertar mais sujeitos para a luta pelo DPD, permitindo um novo olhar sobre a prática colaborativa da educação. Compreendem que não é concebível aceitar uma autonomia ilusória e que é preciso que sejamos intelectuais críticos. Ressaltando por fim, que as condições de trabalho 
adequadas são necessárias a fim de que aconteça uma educação efetiva capaz de responder as demandas do mundo globalizado.

O capítulo de autoria de Ivete Borges Gomes Carvalho, Jusceleide Moreira de Souza, Sérgio Gomes Carvalho e Sibele Shirley da Silva Moura Nery realiza uma análise reflexiva acerca das Políticas Públicas Educacionais na contemporaneidade. Conceituam o que é política pública, discutindo a sua construção, implementação, fragilidades e desdobramentos na educação brasileira mediante a ação do estado. Concluem que as políticas públicas educacionais são essenciais para a garantia do direito à educação para todos, além de servirem para avaliar e melhorar a qualidade do ensino do país. Destacam a garantia dessas políticas pela Lei n 9.394/96, ressaltando que as existências das mesmas dependem do contexto em que são criadas.

A obra faz uma discussão muito importante para o campo educacional, pois em cada um dos artigos são apresentadas diferentes perspectivas acerca da profissão docente. Os desafios apontados pelos autores reforçam a ideia de que mesmo após tantas lutas e resistências, os professores continuam sendo desvalorizados e ainda há uma ausência de qualidade no processo de formação inicial e continuada do professor.

Sob a ótica do neoliberalismo, a educação é uma ferramenta mercadológica nas mãos do capital, portanto, as políticas públicas educacionais que existem hoje se caracterizam como políticas pensadas no favorecimento do mercado. A educação baseada nessa lógica se caracteriza como algo tecnicista, tradicional e reprodutivista. Hoje os profissionais docentes, além de lutarem pelos seus direitos, ainda enfrentam no dia a dia, os desafios de uma educação mercantilista.

Recebido em: 24 de janeiro de 2021 Aprovado em: 07 de fevereiro de 2021 Publicado em: 08 de fevereiro de 2021 